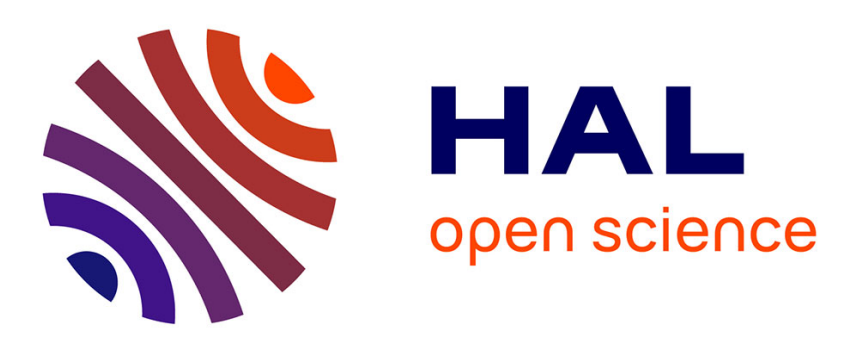

\title{
Slot/pole Combinations Choice for Concentrated Multiphase Machines dedicated to Mild-Hybrid Applications
}

\author{
Bassel Aslan, Eric Semail, Julien Korecki, Jerôme Legranger
}

\section{To cite this version:}

Bassel Aslan, Eric Semail, Julien Korecki, Jerôme Legranger. Slot/pole Combinations Choice for Concentrated Multiphase Machines dedicated to Mild-Hybrid Applications. IECON'11, IEEE International Conference On Industrial Applications of Electronics,, Nov 2011, Australia. pp.3698-3703, 10.1109/IECON.2011.6119910 . hal-00817636

\section{HAL Id: hal-00817636 \\ https://hal.science/hal-00817636}

Submitted on 25 Apr 2013

HAL is a multi-disciplinary open access archive for the deposit and dissemination of scientific research documents, whether they are published or not. The documents may come from teaching and research institutions in France or abroad, or from public or private research centers.
L'archive ouverte pluridisciplinaire HAL, est destinée au dépôt et à la diffusion de documents scientifiques de niveau recherche, publiés ou non, émanant des établissements d'enseignement et de recherche français ou étrangers, des laboratoires publics ou privés. 


\title{
Slot/pole Combinations Choice for Concentrated Multiphase Machines dedicated to Mild-Hybrid Applications
}

\author{
B. Aslan ${ }^{(1,2)}$, E. Semail ${ }^{(1)}$, J. Korecki ${ }^{(1)}$, J. Legranger $^{(2)}$ \\ ${ }^{(1)}$ Arts et Metiers Paristech - L2EP, 8 Bd Louis XIV, 59046 Lille France \\ ${ }^{(2)}$ VALEO-EEM, 2 rue André Boulle, 94000 Créteil France \\ bassel.aslan@valeo.com
}

\begin{abstract}
This paper presents multiphase permanent magnet machines with concentrated non-overlapped winding as a good candidate for automotive low voltage mild-hybrid applications. These machines often require a trade-off between low speed performances such as high torque density and high speed performances like flux weakening capabilities. This paper describes how to choose a key design parameter to ease this compromise, the slots/poles combination, according to three parameters: winding factor including harmonics factor, rotor losses amount thanks to a comparison factor, and radial forces balancing. The comparison criterions are based on both analytical formula and Finite Element Analysis.
\end{abstract}

\section{INTRODUCTION}

For mild-hybrid automotive, in order to achieve a smooth and cheap transition between classical automotive $12 \mathrm{~V}$ low voltage and industrial DC voltage of a few hundred Volts, medium voltage of $60 \mathrm{~V}$ can appear as an interesting solution because of easier and cheaper battery management and also use of family of low-voltage MOSFET transistors with very low $\mathrm{R}_{\mathrm{DSON}}$ resistance and no threshold for the voltage drop.

For a given power, the drawback of low voltage is a higher current per phase. As consequence, it can be necessary to use several transistors in parallel in order to ensure the required current per phase. A better solution for global sizing can be to use a machine with more than three phases [1]-[2]. The use of a single transistor can be interesting for reliability of a Voltage Source Inverter (VSI) leg. Moreover, if one phase is open-circuited it is still possible to work in fault mode but with a lower power [3]-[6]. Other interest of multiphase traction drives with wide speed range [7] appears when square-wave VSI control is used at high speeds, because of harmonics properties, there are lower pulsating torques and as consequence a lower pulsating current in DCbus [8].

Besides, numerous studies have been done on concentrated windings machines [9] when compactness and high efficiency are requested as it is for traction [7] and starter/generator [1] applications of hybrid automotive. Generally, in those applications, the high ratio power/volume is the most important condition especially when the machine should replace the classical clawpole generator of the vehicle in motor/generator case. If winding factors and torque quality [10]-[12] must be considered as it is with distributed windings, other effects, usually less important and considered as parasitic for machines with distributed windings, can become unacceptable for machines with concentrated windings at high speeds (16000 RPM) such as rotor losses and noise. Furthermore, large flux weakening region which allows reaching high speeds and keeping a constant power is needed. Numerous analysis have been done [13]-[20], considering these effects and leading finally to a reduced number of interesting solutions if the number of phases is kept to three. As consequence, considering the number of phases as a parameter of design [21] is a way to increase the number of potential solutions. A few elements of analysis have been given in [22] taking MMF harmonics into account.

This paper presents a comparison which takes into account simultaneously the main effects that influence the final choice for a multiphase machine with concentrated windings. The comparison is based on analytical and numerical analysis. A methodology of design for this family of multiphase machines is thus implicitly proposed.

In the first section we present the results of winding factor calculation of many interesting slots/poles combinations both for the first and third harmonics. Those calculations are done for 5 and 7-phase machines and the case of 3-phase machines is reminded.

In a second part, analytical study is done to investigate the effect of MMF and its harmonics distribution on rotor losses. Analytic losses indicator is identified and calculated to compare between combinations.

The third section considers cogging torque and mechanical balancing.

In the last section, Finite Element Method program is used to study four structures considered as interesting thanks to the analytical analysis. The results confirm the previous comparisons.

\section{WINDING FACTOR}

In this paragraph the winding factor for many feasible combinations of multiphase machine is calculated.

The winding factor is calculated for concentrating and non-overlapped winding. For a given poles/slots combination, the double layer solution is favoured except if the single layer solution has a higher winding factor. It is due to its advantages in rotor losses and mechanical balancing [11], [16], [18]-[19].

The calculation principle depends on the distribution of the slots windings in the electrical space [22]. Every winding is presented by one vector or phasor, whereas the winding 
factor is identified from the sum of vectors which belong to one phase, as we can see in equation (1).

$K_{v}=\frac{1}{Z} \sum_{k=1}^{Z} \cos \left(\alpha_{k}\right)$

$K_{v}$ : winding factor of harmonic $v ; Z$ :number of phasors $\alpha_{k}$ : the angle of the phasor number $k$

There are many possibilities to distribute the phasors in the electrical space, but in our study we search and consider the phasors distribution which produce maximum winding factor. In case of 5 and 7-phase machines, the third harmonic can be used to produce additional constant torque. Therefore, the winding factor of the third harmonic has been calculated also.

The TABLE I represents the winding factor(s) of many combinations for 3, 5 and 7-phase machines. Three families have been distinguished by colors, depending on the value of the winding factor.

In TABLE I, it appears that in order to get combinations with high winding factor (in yellow) then a higher pole number is needed with a corresponding increase of the number of slots. Moreover high winding factor is achieved when the relation "pole number $=\operatorname{slots} \pm 1$ or $=\operatorname{slots} \pm 2$ " is verified. It is due to the almost opposite distribution of every two successive slots phasors in the electrical space [10].

TABLE I

WINDING FACTOR CALCULATIONS

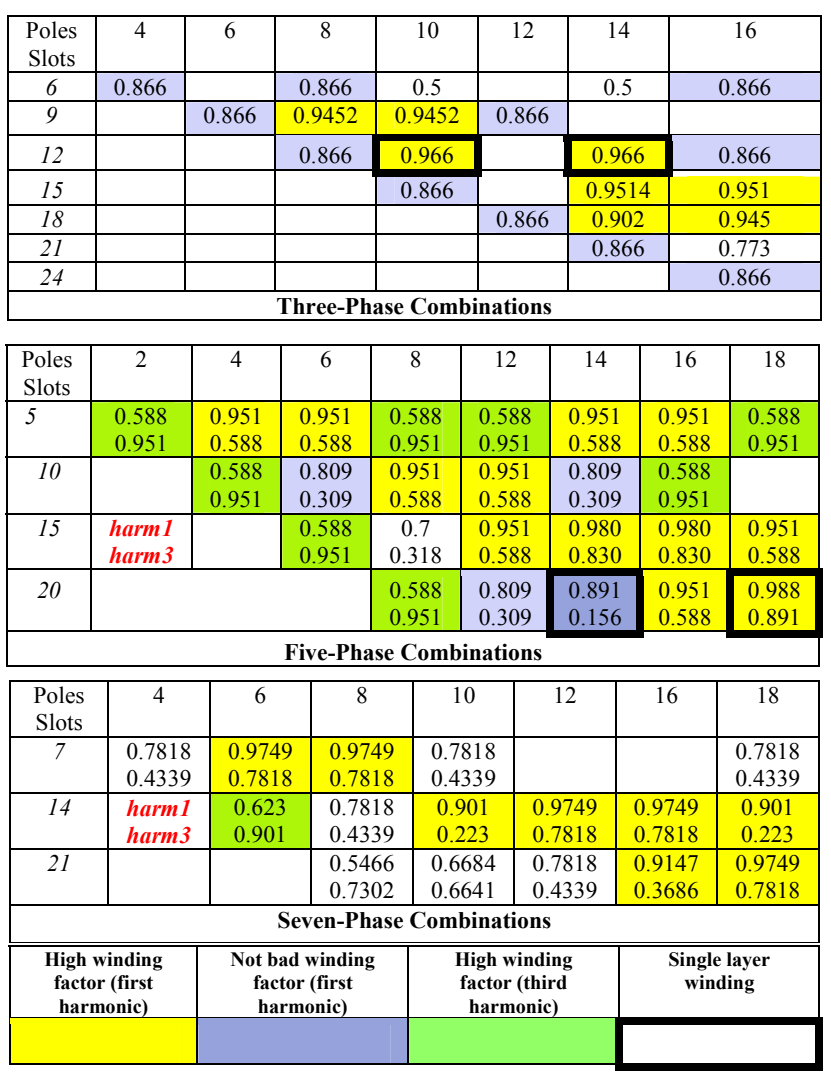

\section{ROTOR LOSSES COMPARISON}

In synchronous permanent magnet machines, eddy current rotor losses in both magnets and iron are the result of the asynchronous movement of the MMF harmonics. In contrary to the fundamental harmonic of MMF whose order is equal to the pole pair number $\mathrm{p}$, the MMF harmonics advance in the air gap in certain speeds different from the rotor one, inducing thus currents in both magnets and rotor iron.

In classical machines with integral slot winding, the MMF harmonics distribution is generally of the type $(2 k+1) h_{f}$ where $h_{f}$ the spatial fundamental harmonic which has the frequency $p$ in the air gap. However, it is not the case in machines made with fractional slot winding [23]. In those machines, the MMF spectrum may have both even and odd harmonics, far and close to the fundamental. Moreover those harmonics may be lower than the fundamental. In this last case, they are called sub-harmonics.

As example, Fig 1 presents the MMF spectrum of 15 slots 14 poles 5-phase machine.

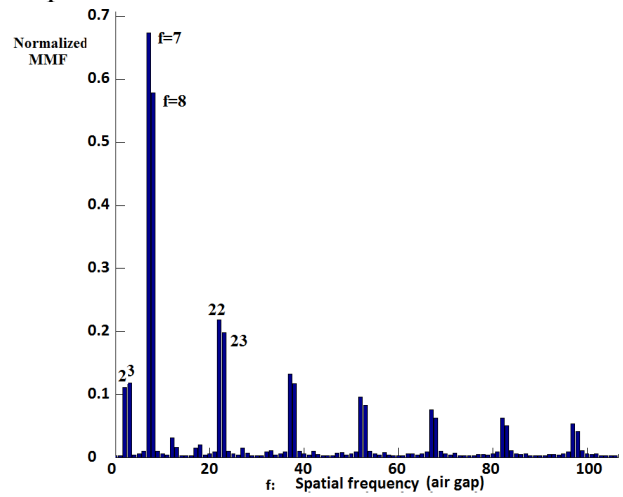

Fig 1. MMF spectrum of 15/14 5-phase combination

It can be noticed that the spatial fundamental harmonic which has the spatial frequency $f=p=7$ in the air gap and just above we can find the harmonic with $f=8$ or in another word the $8 / 7$ harmonic according to the first fundamental one. Moreover, in Fig 1 it can be noted the existence of subharmonics which have the frequency of 2 and 3 in the air gap or $2 / 7$ and $3 / 7$ harmonics according to the fundamental.

Every asynchronous harmonic or sub harmonic of MMF forms an advancing wave in the air gap. The sub harmonics which have the lowest frequency in the air gap move faster than the rotor, while the normal higher harmonics move slower than the rotor. Consequently for each harmonic or sub harmonic, there are three important factors which decide of the effect of this harmonic on eddy current rotor losses. Those factors are: amplitude; moving direction and speed.

The harmonic speed and direction are necessary to calculate the relative speed of this harmonic according to rotor which is the source of induced eddy currents.

This relative speed of every harmonic $v$ can be calculating using the equation (2) [16], [23]: 


$$
\omega_{v r}=\frac{\omega}{\operatorname{sgn}(v) v}-\frac{\omega}{p}
$$

where $\omega_{v r}$ is the relative pulsation of the harmonic $v, \omega$ is the electric pulsation, and sgn is the sign of the harmonic movement $(+1$ in the same direction as the rotor -1 in the opposite direction). The last equation can be rewritten, considering the mechanical rotation frequency $f_{\text {rotor }}$ :

$$
f_{v r}=f_{\text {rotor }}\left(\frac{p}{\operatorname{sgn}(v) \cdot v}-1\right)
$$

where $f_{v r}$ the relative frequency of harmonic $v$.

It can be noted that the fundamental harmonic $v=p$ has a zero relative frequency, while there are two types of harmonics which have a high relative frequency and could be a possible source of eddy currents losses in the rotor:

- Sub harmonics which are far behind the fundamental $(v<<p)$

- Harmonics $(v>p)$ and sub-harmonics $(v<p)$ close to the fundamental ( $v$ close to $p$ ) and moving in the opposite of rotor direction. In this case, the relative frequency is almost twice the rotor mechanical frequency.

The other harmonics, far ahead the fundamental, have a relative frequency almost equal to rotor mechanical frequency due to their slow spatial speeds.

In order to compare the rotor eddy current losses between different combinations, an indicator is developed using the equation (4) on an estimation of the losses induced by a magnetic flux density $B$ which varies with the frequency $f$ [22]:

Eddy Current Losses $=k_{e} B^{2} f^{2}$ with $k_{e}$ constant

Considering a given level of magnetic flux density $B_{\text {fund }}$ in the air gap, a global indicator $I_{E d d y \text { Losses }}$ is calculated:

$$
I_{\text {eddy losses }}=B_{\text {fund }}^{2} f_{\text {rotor }}^{2} \sum_{v} \frac{B^{2}{ }_{v}}{B^{2} \text { fund }}\left(\frac{p}{\operatorname{sgn}(v) \cdot v}-1\right)^{2}
$$

where $B_{\text {fund }}, B_{v}$ are respectively the magnetic flux density amplitude of the fundamental and of the $v$ harmonic resulting from the MMF stator currents. In (5), it is supposed that the eddy current losses for each harmonic $v$ can be added to give the total eddy losses.

Supposing that all examined machines have the same magnetic flux density of the fundamental harmonic $B_{\text {fund }}$, we can use this indicator to compare, for a given rotor frequency $f_{\text {rotor }}$, the amount of eddy current losses between different combinations.

TABLE II represents the ranges of calculated indicator $I_{E d d y \text { Losses }}$ for different previous combinations considering the winding topology which leads to the same winding factors in TABLE I. Green combinations in which the indicator value is lower than 1 have the minimum rotor losses, while red combinations with indicator is higher than 4 produce high eddy current rotor losses

It can be easily noticed that there is a family of combination which have the lowest indicator, it is the family which has the number of slots per pole and per phase equal to $0.5(q=0.5)$.To analyse this result the MMF generation in this family is studied.

The periodicity $t$ in fractional slot winding machine is identified as [24]:

$$
t=G C D\left(Q_{s}, p\right)
$$

$G C D$ : greatest common divisor and $Q_{s}$ : number of slots.

If the periodicity of the machine is equal to $p$, the winding pattern could be distributed and repeated $p$ times around the air gap. Consequently the most important harmonic in the produced MMF is the fundamental harmonic of order $p$, and moreover the spectrum is clean from sub-harmonics either from harmonics close to fundamental.

This means that to get such MMF it is enough to verify:

$$
t=G C D\left(Q_{s}, p\right)=p
$$

Then it can be written:

$$
\begin{array}{ll}
Q_{s}=k \cdot p & , k \in N^{*} \\
q=\frac{Q_{s}}{2 \cdot p \cdot m}=\frac{k}{2 \cdot m} & , m: \text { phase number }
\end{array}
$$

It can be proved that the only solutions which lead towards a feasible symmetric structure with $(q<1)$ are when $k=m$

\begin{tabular}{|c|c|c|c|c|c|c|c|}
\hline $\begin{array}{l}\text { Poles } \\
\text { Slots }\end{array}$ & 4 & 6 & 8 & 10 & 12 & 14 & 16 \\
\hline 6 & & & & & & & \\
\hline 9 & & & & & & & \\
\hline 12 & & & & & & & \\
\hline 15 & & & & & & & \\
\hline 18 & & & & & & & \\
\hline 21 & \multicolumn{3}{|c|}{ 3-Phase } & & & & \\
\hline 24 & & & & & & & \\
\hline
\end{tabular}
with $\mathrm{q}=0.5$ as consequence.

\begin{tabular}{|c|c|c|c|c|c|c|c|c|}
\hline $\begin{array}{l}\text { Poles } \\
\text { Slots }\end{array}$ & 2 & 4 & 6 & 8 & 12 & 14 & 16 & 18 \\
\hline 5 & & & & & & & & \\
\hline 10 & & & & & & & & \\
\hline 15 & & & & & & & & \\
\hline 20 & \multicolumn{3}{|c|}{ 5-Pha } & & & & & \\
\hline
\end{tabular}

If the winding factor is high for $\mathrm{q}=0.5$ then the configuration is interesting: it is the case for 3-phase machines but not for 5 and 7-phase machines (see TABLE II).

TABLE II

CLASSIFICATION BY EDDY CURRENT LOSSES INDICATOR VALUES

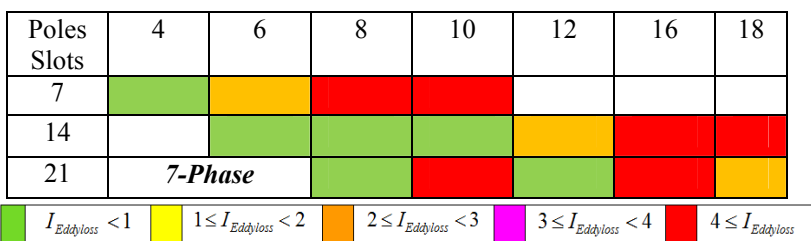




\section{MECHANICAL BEHAVIOUR}

\section{A. Cogging torque}

In fractional slot winding machine the combination slots/poles plays the main role in deciding the cogging torque amplitude. The frequency of this cogging torque in an internal mechanical turn can be calculated by the equation (9) [12].

$$
f_{\text {cogging }}=\operatorname{LCM}\left(Q_{s}, 2 . p\right)
$$

$L C M$ : Least common multiple, $Q_{s}$ : number of slots

When the frequency of the cogging torque increases, the amplitude of oscillation decreases owing to the fact that magnetic power is changing more smoothly around the air gap, therefore it is better to get a combination with the higher possible $L C M\left(Q_{s}, 2 p\right)$. On the other hand, it can be noticed in TABLE II that the combinations with high $\operatorname{LCM}\left(Q_{s}, 2 p\right)$ and low cogging torque amplitudes have a low periodicity $t=G C D\left(Q_{s}, p\right)=1$. As consequence, their MMF contains sub-harmonics and harmonics which are close to the fundamental harmonics. Hence they produce high eddy current rotor losses compared with other combinations.

\section{B. Unbalanced Radial forces}

One of the parasitic effects in fractional slot winding machine is the unbalanced radial forces because of irregular MMF distribution. In fact, the configuration of coils which belong to the same phase in the slots decides the distribution of radial forces around the rotor. Consequently the combinations in which every phase is located in one side of the stator are mechanically unbalanced, while we get more balanced combinations when the phase coils are regularly distributed along the slots.

The rotor or stator under unbalanced radial forces can be mechanically considered as a metal ring with different radial vibration mode shapes, as illustrated in Fig 2.
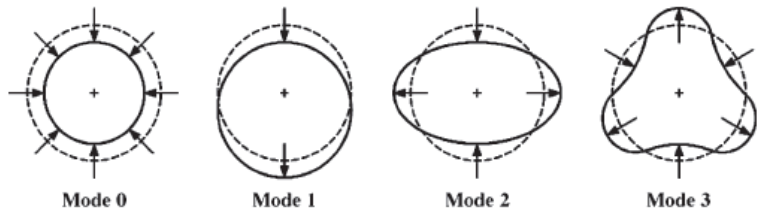

Fig 2. Different vibration modes shape order

In Fig 2, it can be noticed that the frequency and the amplitude of the radial vibrations (because of rotor or stator deflection) depend on the vibration mode shape [12]. Consequently, combinations with phase coils well distributed around the stator have a high order vibration mode with lower amplitude and higher frequency, which is generally better because relatively low frequency vibration can cause a resonance with the machine natural frequency.

TABLE III presents the order of vibration mode shape for the previous slots/poles combinations considering the same winding topology which leads to winding factors represented in TABLE II

The vibration modes presented in TABLE III are deduced from the distribution of a single phase coils in every combination which is equivalent to the instantaneous radial forces configuration around the rotor.
TABLE III

VIBRATION MODE SHAPE ORDER

\begin{tabular}{|c|c|c|c|c|c|c|c|}
\hline $\begin{array}{l}\text { Poles } \\
\text { Slots }\end{array}$ & 4 & 6 & 8 & 10 & 12 & 14 & 16 \\
\hline 6 & 2 & & 2 & 2 & & 2 & 2 \\
\hline 9 & & 3 & 1 & 1 & 3 & & \\
\hline 12 & & & $\mathrm{HO}$ & 2 & & 2 & $\mathrm{HO}$ \\
\hline 15 & & & & $\mathrm{HO}$ & & 1 & 1 \\
\hline 18 & \multicolumn{3}{|c|}{ 3-Phase } & & $\mathrm{HO}$ & 2 & 2 \\
\hline 21 & & & & & & $\mathrm{HO}$ & Irreg \\
\hline 24 & \multicolumn{4}{|c|}{ HO: High Order Mode $>3$} & & & $\mathrm{HO}$ \\
\hline
\end{tabular}

\begin{tabular}{|c|c|c|c|c|c|c|c|c|c|}
\hline $\begin{array}{c}\text { Poles } \\
\text { Slots }\end{array}$ & $\mathbf{2}$ & $\mathbf{4}$ & $\mathbf{6}$ & $\mathbf{8}$ & $\mathbf{1 0}$ & $\mathbf{1 2}$ & $\mathbf{1 4}$ & $\mathbf{1 6}$ & $\mathbf{1 8}$ \\
\hline $\mathbf{5}$ & 1 & 1 & 1 & 1 & & 1 & 1 & 1 & 1 \\
\hline $\mathbf{1 0}$ & & 2 & 2 & 2 & & 2 & 2 & 2 & \\
\hline $\mathbf{1 5}$ & & & 3 & & & 3 & 1 & 1 & 3 \\
\hline $\mathbf{2 0}$ & \multicolumn{2}{|c|}{5 -Phase } & & HO & & HO & 2 & HO & 2 \\
\hline
\end{tabular}

\begin{tabular}{|c|c|c|c|c|c|c|c|}
\hline $\begin{array}{c}\text { Poles } \\
\text { Slots }\end{array}$ & $\mathbf{4}$ & $\mathbf{6}$ & $\mathbf{8}$ & $\mathbf{1 0}$ & $\mathbf{1 2}$ & $\mathbf{1 6}$ & $\mathbf{1 8}$ \\
\hline $\mathbf{7}$ & 1 & 1 & 1 & 1 & & & 1 \\
\hline $\mathbf{1 4}$ & & 2 & 2 & 2 & 2 & 2 & 2 \\
\hline $\mathbf{2 1}$ & \multicolumn{2}{|c|}{ 7-Phase } & Irregular & Irregular & 3 & Irregular & 3 \\
\hline
\end{tabular}

\section{FINITE ELEMENTS COMPARISON}

In this paragraph, four combinations are chosen from the previous tables to be compared with, using a commercial software ("Maxwell") based on the Finite Element Method.

- 18 slots/12 poles 3-phase machine

- 15 slots/12 poles and 20 slots/12 poles 5-phase machines

- 14 slots/12 poles 7-phase machine

The combinations are chosen with the same $p$, with high winding factor (higher than 0.8 ), and for three different rotor losses indicators (TABLE II.)

For comparison, four magnetic 2D-models are built considering the following assumptions:

A. All machines have the same linear current density, the same magnetic flux density in the air gap, and the same rotor.

B. All machines are designed to produce the same average torque (50 N.m.), considering sinusoidal flux density model, and a winding factor equal to 1 in all the models.

Then the only difference between the models is the slots number and the winding topology.

Fig 3 presents the structures of the four machines, with the winding topologies. All machines are provided with a double layer concentrated non overlapped winding, while the rotor is the same with internal radial permanent magnets. Fig 5 illustrates the average torque of these four machines calculated by the FEM program during one electrical period in full load case. The torque is the result of shifted sinusoidal currents (fundamental harmonic) that have the same phase as the Back-EMF in order to consider only the maximum electromagnetic torque whose reluctance effect are negligible.

It can be seen that the generated torques are arranged according to the winding factors of the models, where higher winding factor implies higher torque thanks to the assumption B. 


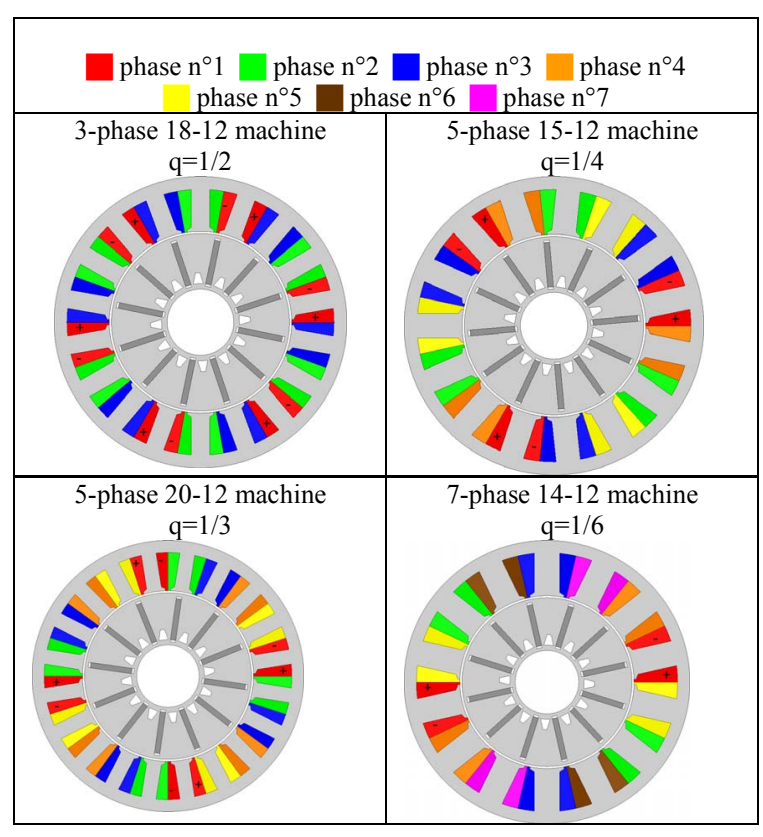

Fig 3. Examined Machines structures

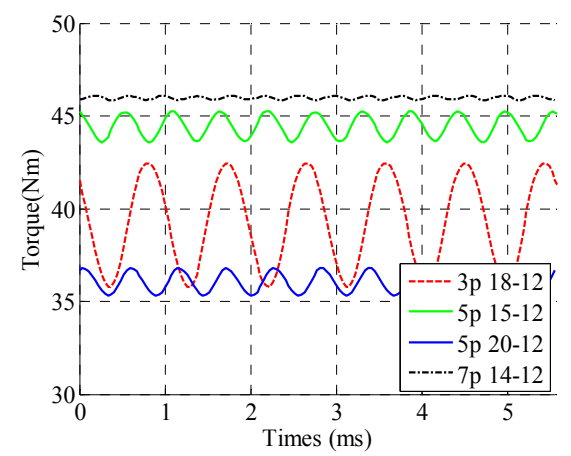

Fig 5. Average torque

Fig 4 shows the cogging torque of the machines during two electrical periods. The simulation is done in no load case at the speed 1800 RPM. It can be noticed that the amplitude and the frequency of cogging torque is almost the same as the torque ripples in Fig 5 which shows the important of cogging torque as the first source of torque oscillations in these 4 structures.

The next point to be compared using Maxwell program is the eddy current magnet losses. Using magnets with bulk conductivity equal to $625000 \mathrm{~S} / \mathrm{m}$ losses are calculated the losses at different rotor speeds. Fig 6 illustrates the normalised calculated eddy current magnet losses in the previous structures at different speeds.

It can be seen how the calculated losses indicator in paragraph 2 gives a good estimation of eddy losses level in each combination. 18/12 three-phase and 20/12 five-phase machines have the lowest magnet losses at all speeds, while 14/12 seven-phase machine has the highest losses, which are in accordance with the colours of losses indicator in TABLE II.

The combination 18/12 three-phase belongs to the family which archives $q=0.5$ with, therefore, low magnet losses. On the other hand, the combination 20/12 can be considered as a good choice in case of 5-phase machine with low eddy current rotor losses but with a lower winding factor of 0.809 .

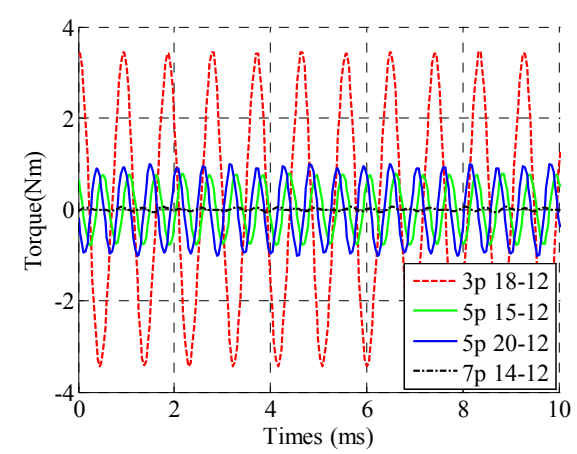

Fig 4. Cogging Torque

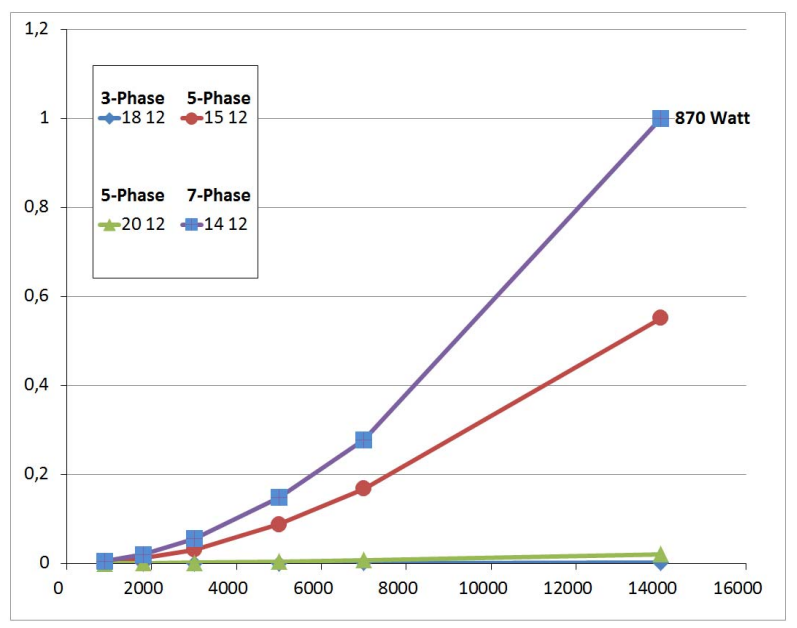

Fig 6. Normalized magnet losses versus mechanical speed

Lastly, and in order to investigate the unbalanced radial forces and the vibration modes of the machines, the mechanical deformation in the rotor is calculated by a coupling between two software, Maxwell and ANSYS, in full load case. The results are illustrated in figure (7). It can be seen that the repetition of calculated mechanical deformation around the rotor corresponds to the expected vibration mode in TABLE III. The combination 18/12 threephase machine shows a well-balanced high order mode with the lowest amplitude of mechanical deformation, while the combination 14/12 seven-phase machine represents the worse mode among the four structures (second mode) with only two opposite forces and the highest mechanical deformation.

\section{CONCLUSION}

This paper helps to choose the suitable slots/poles combination for 3, 5, and 7-phase fractional slot concentrated winding machines.

The maximum winding factor that could be obtained from each combination is calculated. The effect of MMF spectrum on eddy current rotor losses is investigated. Moreover using the winding topology and MMF spectrum a comparison indicator of rotor losses is identified. Generally the results show that combinations with high winding factor 
(factor $>0.9$ ) produce much more rotor losses comparing to those with lower winding factor $(0.9>$ factor $>0.75)$. 18-12

High order mode
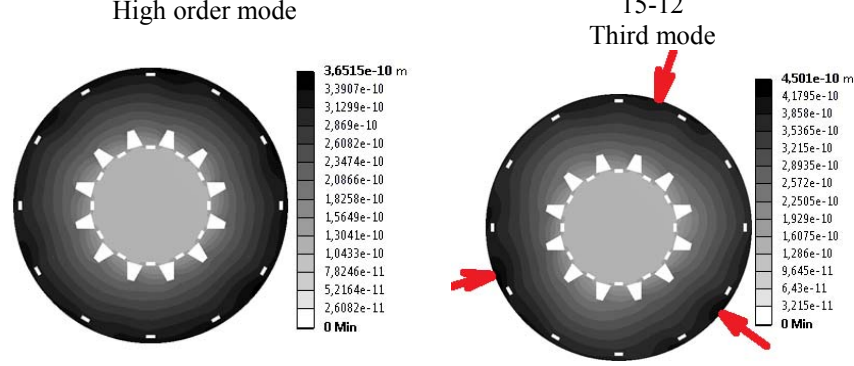

$20-12$
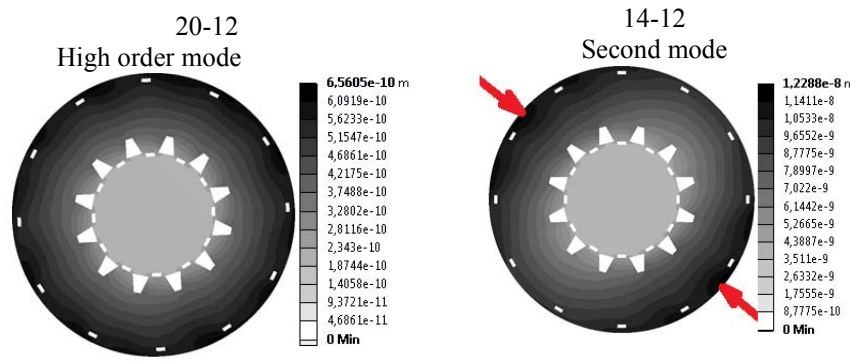

Fig 7. Mechanical Deformation

This means that for high speed traction applications where rotor losses can reach high inacceptable levels (causing magnets damage) it is preferable to use combinations of lower winding factor which cause lower rotor losses like 3phase 18/12, 5-phase 20/12, and 7-phase 14/10.

Besides that, cogging torque and mechanical radial forces of different combinations are studied. Here it is found that combinations which produce relatively low cogging torque generally have high winding factor but at the same time high rotor losses like in the case of 7-phase 14/12. On the other hand, machines with lower rotor losses are mechanically more balanced like in the case of 3-phase 18/12. In summary this table shows the existence of two families of combinations.

\begin{tabular}{|l|c|c|c|}
\hline & Winding Factor & Rotor Losses & Cogging Torque \\
\hline Family 1 & ++ & -- & ++ \\
\hline Family 2 & + & ++ & -- \\
\hline
\end{tabular}

\section{ACKNOWLEDGMENT}

Acknowledgment for ADEME funding for MHYGALE project.

\section{REFERENCES}

[1] A. Bruyere, E. Semail, A. Bouscayrol, F. Locment, J.M. Dubus, J.C. Mipo, "Modeling and control of a seven-phase claw-pole integrated starter alternator for micro-hybrid automotive applications," Proc. of VPPC '08., IEEE Vehicle Power and Propulsion Conf., China, Sept. 2008

[2] E.Levi, "Multiphase electric machines for variable-speed applications," IEEE Trans. on Industrial Electronics, vol. 55, no. 5, 2008, pp. $1893-$ 1909.

[3] M. Abolhassani, "A novel Multiphase Fault Tolerant High Torque Density Permanent Magnet Motor Drive for Traction Application", Proc. of IEEE-IEMDC'05, IEEE International Electric Machines \& Drives Conference, USA, May 2005.
[4] L. Parsa, H. A. Toliyat, "Fault-Tolerant Interior-Permanent-Magnet Machines for Hybrid Electric Vehicle Applications", IEEE Trans. on Vehicular Technology, vol.56, no.4, pp.1546-1552, July 2007.

[5] O. Wen, T.A. Lipo, "Modular Permanent Magnet Machine with Fault Tolerant Capability," Proc. of IEEE APEC Applied Power Electronics Conference and Exposition, pp.930-937, Feb. 2009.

[6] F. Locment, E. Semail, X. Kestelyn, "Vectorial approach-based control of a seven-phase axial flux machine designed for fault operation", IEEE Trans. on Industrial Electronics, vol. 55, no. 10, Oct. 2008, pp.36823691.

[7] A.M. EL-Refaie, J.P. Alexander, S. Galioto, M.R. Shah, Huh KumKang, W.D. Gerstler, J. Tangudu, T.M. Jahns, "Scalable, low-cost, high performance IPM Motor for Hybrid Vehicles," Proc. of ICEM'10 International Conference on Electrical Machines, Italy, Sept. 2010.

[8] F. Locment, A. Bruyere, E. Semail, X. Kestelyn, A. Bouscayrol, J.M. Dubus, "Comparison of 3-, 5- and 7-leg Voltage Source Inverters for low voltage applications," Proc. of IEMDC'07, IEEE International Electric Machines \& Drives Conference, vol.2, pp.1234-1239, Turkey, 2007.

[9] A.M El-Refaie, «Fractional-Slot Concentrated-Windings Synchronous Permanent Magnet Machines: Opportunities and Challenges", IEEE Trans. on Industrial Electronics, Vol. 57, No. 1, January 2010.

[10] J. Cros, P. Viarouge, "Synthesis of high performance PM machines with concentrated windings," IEEE Trans. on Energy Conversion, vol. 17, no. 2, pp. 248-253, 2002.

[11] N. Bianchi, S. Bolognani, M.D. Pre, G. Grezzani, "Design considerations for fractional-slot winding configurations of synchronous machines," IEEE Trans. on Industry Applications, vol.42, no.4, pp. $997-$ 1006, July-Aug. 2006.

[12] E. Fornasiero, L. Alberti, N. Bianchi, S. Bolognani, "Considerations on selecting fractional-slot windings," Proc. of ECCE, IEEE Energy Conversion Congress and Exposition, Sept. 2010, pp.1376-1383.

[13] F. Magnussen, H. Lendenmann, "Parasitic Effects in PM Machines with Concentrated Windings," IEEE Trans. on Industry Applications, vol.43, no.5, pp.1223-1232, Sept-Oct. 2007.

[14] R. Wrobel, P.H. Mellor, "Design Considerations of a Direct Drive Brushless Machine with Concentrated Windings," IEEE Trans. on Energy Conversion, vol.23, no.1, pp.1-8, March 2008.

[15] Z. Q. Zhu, "Fractional Slot Permanent Magnet Brushless Machines and Drives for Electric and Hybrid Propulsion Systems", Proc. of EVER, International Congress, Monaco, 2009.

[16] N. Bianchi, E. Fornasiero, "Impact of MMF Space Harmonic on Rotor Losses in Fractional-Slot Permanent-Magnet Machines", IEEE Trans. on Energy Conversion, vol.24, no.2, pp.323-328, June 2009.

[17] N. Bianchi, E. Fornasiero, "Index of rotor losses in three-phase fractional-slot permanent magnet machines," IET Electric Power Applications, vol.3, no.5, pp.381-388, Sept. 2009.

[18] N. Bianchi, S. Bolognani, E. Fornasiero, "An Overview of Rotor Losses Determination in Three-Phase Fractional-Slot PM Machines," IEEE Trans. on Industry Applications, vol.46, no.6, pp.2338-2345, Nov.-Dec. 2010.

[19] Z. Q. Zhu, Z.P. Xia, L. J. Wu, G.W. Jewell, "Influence of Slot and Pole Number Combination on Radial Force and Vibration Modes in Fractional Slot PM Brushless Machines Having Single- and Double layer Windings », Proc. of ECCE, IEEE Energy Conversion Congress and Exposition, USA, Sept.2009.

[20] H. Seok-Hee, T.M. Jahns, Z.Q. Zhu, "Analysis of Rotor Core EddyCurrent Losses in Interior Permanent-Magnet Synchronous Machines," IEEE Trans. on Industry Applications, vol.46, no.1, pp.196-205, Jan.feb. 2010

[21] F. Scuiller, E. Semail, J.-F Charpentier, "General modeling of the windings for multi-phase AC machines", EPJ. Applied physics, ISSN 1286-0042, 2010.

[22] E. Fornasiero, N. Bianchi, S. Bolognani, "Rotor losses in fractional-slot three-phase and five-phase PM machines", Proc. of ICEM'10, International Conference on Electrical Machines, Italy, Sept. 2010.

[23] J.Pyrhonen, T. Jokinen, V. Hrabovcova, "Design of rotating electrical machines", $1^{\text {st }}$ edition, Wiley, Book, 2008.

[24] N. Bianchi, S. Bolognani, E. Fomasiero, "A General Approach to Determine the Rotor Losses in Three-Phase Fractional-Slot PM Machines" Proc of IEMDC 07, IEEE International Electrical Machines and Drives Conference, Turkey, 2007. 